\title{
The PPP Financing Model of Jingdezhen Imperial Kiln Site Protection and Research
}

\author{
Qun Wei
}

\author{
University of Jingdezhen Ceramics, Jingdezhen, 333403, Jiangxi province, China
}

Key words: the PPP financing model, imperial kiln site, site protection

\begin{abstract}
PPP financing model can alleviate Jingdezhen imperial kiln site project to protect the capital bottleneck, realize the diversification of investment, to ensure the Jingdezhen imperial kiln site, on the basis of effective protection, promote the smooth development and operation of the project. In this paper, the Jingdezhen imperial kiln site to protect the PPP financing model has carried on the feasibility analysis, for the Jingdezhen imperial kiln site protection, first proposed the idea of PPP financing model, in order to Jingdezhen imperial kiln site lay the solid foundation to become the world's cultural heritage, prompting Jingdezhen unique cultural relics and heritage protection work to a new level, and bring new development opportunities for Jingdezhen and jiangxi province, and other relics protection project for the development of provides the certain reference significance.
\end{abstract}

\section{Introduction}

Jingdezhen imperial kiln site is the only can reflect the comprehensive system in our country historical heritage kiln ceramic culture production information, all over the world have irreplaceable historical, scientific, cultural and artistic value. Her protection and exploitation and utilization is of great significance for China and the world. And the protection and exploitation and utilization is inseparable from the capital investment, if only rely on the government funds investment, financing channel is less, is bound to appear in the long-term protection of the capital chain rupture, this needs to seek a feasible long-term financing mode. The PPP financing risk-sharing, benefit sharing win-win model get the wide recognition and promotion of the world. PPP financing model (Public Private Partnerships), also known as the government and the cooperation pattern, social capital refers to the government through the franchise, reasonable pricing and Public benefits agreed rules of fiscal subsidy, the introduction of social capital to participate in Public welfare undertakings of investment and operation, advantages and win-win for both sides, realize the diversification of investment, ensure the efficient and effective protection to the Jingdezhen imperial kiln site, on the basis of smooth development and operation of the project, prompting Jingdezhen unique cultural relics and heritage protection work to a new level, and bring new opportunities for development of Jingdezhen and jiangxi。

\section{The PPP financing model research present situation analysis}

Look around the world, since the 1980 s, Britain, Australia, Canada and other countries began to explore the use of the PPP mode, attract social capital to participate in infrastructure construction and operation, accumulated the rich practical experience, a more advanced system. The PPP financing model research mainly concentrated in agriculture, transportation, pensions, infrastructure, medical and health care, housing, and other fields of applied research. The G20, APEC meeting, have initiative, widespread adoption of the PPP model in infrastructure field. In China hownet to search topic of "the PPP financing model", articles published before 2015 in total also has more than hundred only. In recent years, countries have issued a series of PPP financing model guidance documents, such as operational guidelines for school official cites use of the mode of government and social capital cooperation (try out) ", "national development and reform commission of the government and social capital cooperation guidance", "the ministry of finance on promoting use of government and social capital on the cooperation pattern of notice, for the PPP financing model 
implementation frameworks and guide, the PPP financing model research has become a hot issue. But in "the PPP financing model" and "heritage" as the theme to search, is almost zero, it is a research gap。

\section{The Jingdezhen imperial kiln site protection feasibility analysis of PPP financing model}

Since the current international financial crisis, in the face of insufficient effective demand, Europe and the United States the main developed countries pay more attention to play a role of the private sector, and actively use the PPP mode increase the supply of public service, to promote economic recovery. The PPP financing model is the development of the economy, the depth of the financial products, original intention is to solve the financing problem, at the same time improve the quality of public goods supply and also played a big role. Jingdezhen imperial kiln site as the carrier, tao and the history of the fire with the only characteristic of non-renewable and do not copy, this requires that we must to properly and effectively protect and promote the inheritance and development of ceramic culture. The PPP financing model was applied to the protection of the Jingdezhen imperial kiln site is feasible, which can effectively alleviate the capital bottleneck problem。

\subsection{It can effectively relieve the bottleneck problem of funds, reduce the financial burden}

At present, the protection of Jingdezhen imperial kiln site, in the process of development and utilization, the required capital mainly comes from the government's financial support of relevant departments, as well as get loans from Banks, financing channel is less, far cannot satisfy the imperial kiln site protection and the sustainable development of the huge funding gap. To imperial kiln site conservation project smoothly, realize the diversification of sources of funds, an urgent need to seek a new financing, namely the PPP financing model (Public - Private Partnership), aimed at easing Jingdezhen imperial kiln site project capital bottleneck problems in protection and development, eliminate cost overruns in Jingdezhen imperial kiln site protection, so as to reduce the financial burden 。

\subsection{It can effectively leads to the transformation of the government function}

PPP financing model, is to absorb the social capital of Jingdezhen imperial kiln site protection services, can make the government free from heavy daily affairs, Jingdezhen imperial kiln site protection service provider from the past into a regulator, thus ensuring the Jingdezhen imperial kiln site protection and reasonable development and utilization, not only ease the government's financial pressure, and effectively improve the service efficiency of funds and develop operational efficiency, improve the efficiency of low produce all sorts of problems. Before the traditional relics protection project, the government are both managers and owners, the private enterprise is by managers, but in the PPP financing mode, government and social capital cooperation, changed the previous command and command, control and be controlled, the relationship between make both formed the unity and cooperation relationship of mutual trust, effectively implement the transformation of government functions and roles。

\subsection{It can effectively disperse the project risk, strengthen risk defense ability}

The PPP financing model of a big advantage is to achieve risk-sharing, make the tourism project participants according to own actual ability to bear the corresponding risks, enjoy equal rights and interests, to obtain the corresponding return, this is more in line with the market economy rule, strengthen tourism project risk resistance ability effectively. Tourism projects tend to encounter various risks in the process of let hair, for example, political risk, legal risk and project completion risk and so on a series of possible contingencies, although the government can relatively RongYang defuse political risks, but in the face of all kinds of unexpected situation and problems in the construction site, the government's capacity is far less than the private sector, therefore, the government and the private sector to follow the processing cost risk minimization principle, respectively for their easy to resolve and avoid risks, to strengthen the ability to resist risk the whole project, to improve the competitive ability of the project 。 


\subsection{It can promote the diversification of investment subject, the effective introduction of market mechanism}

General site protection project is in government hands, is individual development by the government, but the government separate its function from one side must have certain limitations, it often leads to protect development project can't well meet the demand of market, not play well in social and economic benefits, is not in conformity with the law of market operation. Blend in the social capital, and use the PPP financing model makes the government departments and social capital cooperation, promote the investment subject pluralism, this not only can bring excellent management talents and experience, and the market competition mechanism, to the Jingdezhen imperial kiln site protection, development and utilization of injected new vitality, conform to the market law of development, improve the efficiency of the ruins of the protection, development and utilization, better meet the economic and social needs 。

\subsection{It can effectively avoid the excessive development of imperial kiln site}

If the government of Jingdezhen imperial kiln site project to let it go, quite in the private sector investment, construction, operation management, will cause its temporary privatization, it will ignore the imperial kiln site project of social public welfare, cause excessive development of Jingdezhen imperial kiln site, will cause great imperial kiln sites of the damage, is more serious is that will cause the destruction of the ceramic history civilization essence, and Jingdezhen imperial kiln site as ceramic culture of the human spirit and material wealth, once the damage will be difficult to repair.

In Jingdezhen imperial kiln site project using the PPP financing model, is Jingdezhen government signed with social capital and business operation entities through a franchise agreement, jointly establish franchise units, the franchise units under the Jingdezhen government supervision, organization of Jingdezhen imperial kiln sites for the construction of the project, protection, development and operation of all process, which can effectively avoid the excessive development of the negative effects of private owned operations, to ensure the public value of Jingdezhen imperial kiln site, realize the value of the project optimization 。

\subsection{It can effectively coordinate the interests of all parties, achieve win-win situation}

PPP financing model, is by the government through the franchise rights, reasonable pricing, financial subsidies, such as public agreed rules in advance, and social capital operations department of Jingdezhen imperial kiln site project cooperation agreement, to the Jingdezhen imperial kiln site monitor all projects to protect the development process, target, coordinating the interests of all parties integration of strategic alliance, complement each other, play to the advantages of the government public institutions and private private institutions, avoid excessive pursuit of economic interests of the individual development, both to protect the Jingdezhen imperial kiln site reasonable development and utilization, and improve the efficiency of the use of social idle funds, improve the private sector, enterprise visibility and reputation, access to social masses of the people, realize the development of the whole protection operation project value achieve pareto optimality, achieve win-win situation on both sides 。

\section{The laws and regulations support}

Since 2014, the state issued the national development and reform commission on the guidance of the government and social capital cooperation, the ministry of finance on promoting use of government and social capital on the cooperation pattern of notice and a series of PPP financing model guidance document, for the PPP financing model implementation frameworks and guide, from the legal norm and safeguard the PPP financing model 。

The Jingdezhen imperial kiln site protect the PPP financing model of operation procedure 


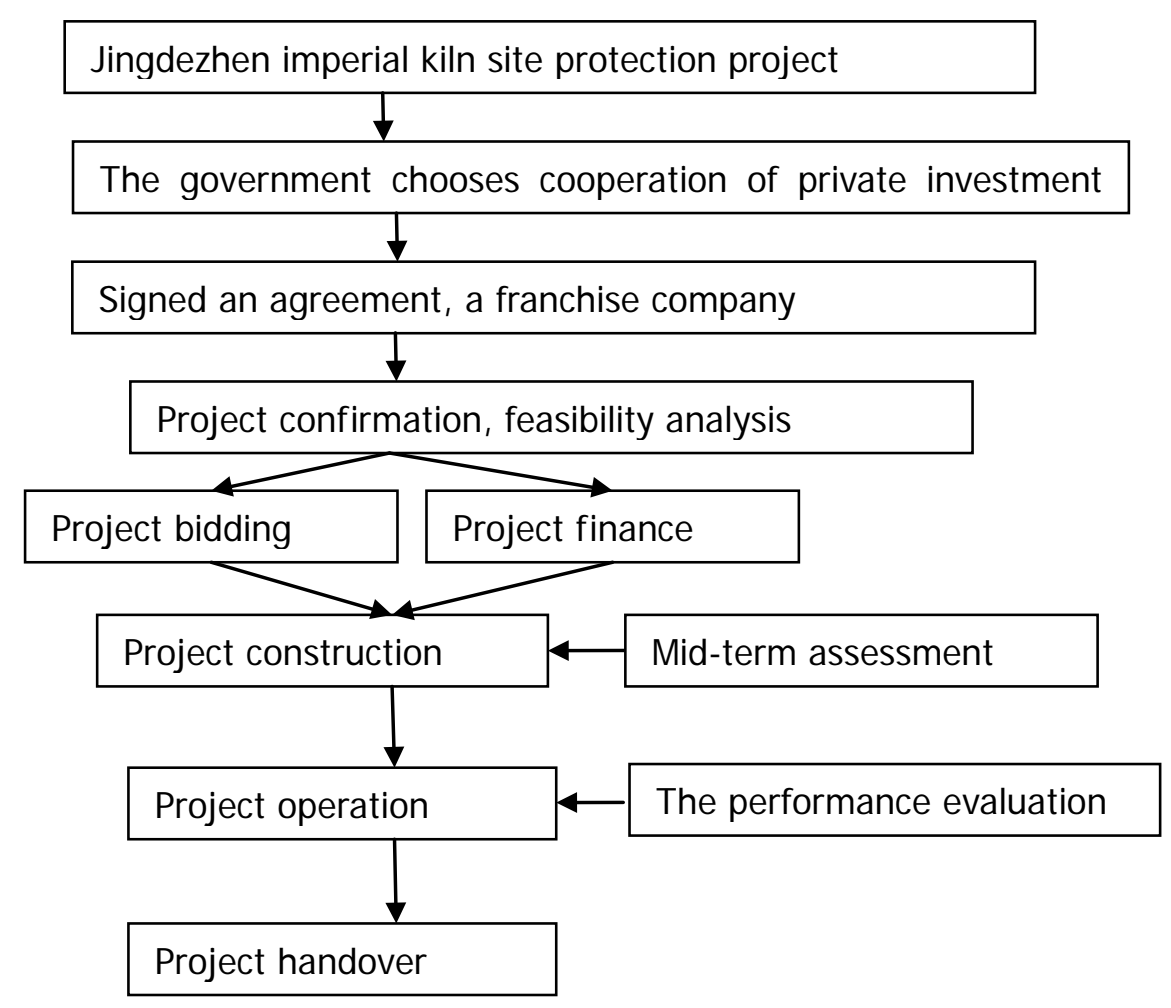

Figure 1 Jingdezhen imperial kiln site to protect the PPP financing model of operation procedure

Jingdezhen imperial kiln site to protect the PPP financing mode of operation process of the project: Jingdezhen government departments or project relevant institutions and social investors or operators and managers through the franchise agreement, a franchise company, the company is responsible for the project financing, construction and management of late, and in accordance with the agreement, undertake project franchising period of the related responsibility and risk, with Jingdezhen imperial kiln site protection management control of the project, related to the business profits, accept the oversight of the department of the government, and after the expiration of the franchise, transfer the project to the Jingdezhen government department or the project belongs to government agencies 。

\section{Jingdezhen imperial kiln site protection risk analysis of PPP financing model}

In the PPP financing mode, Jingdezhen imperial kiln site conservation project development period and investment payback period is long, and greatly influenced by external factors, compared with other of the PPP projects, risk is often larger, therefore, the risk analysis is very important. Whether for department of Jingdezhen government or with social capital, it is necessary to evaluate the entire Jingdezhen imperial kiln site protection potential risks existing in the project life cycle, to ensure the protection under the premise of Jingdezhen imperial kiln site, as far as possible to reduce possible risks in the process of development and utilization。 
Table 1 Jingdezhen imperial kiln site protection risk analysis of PPP financing model table

\begin{tabular}{|c|c|}
\hline The risk types & Specific risk \\
\hline $\begin{array}{l}\text { Project } \\
\text { decision-making } \\
\text { risk }\end{array}$ & Market research, feasibility study, risk \\
\hline $\begin{array}{l}\text { Project } \\
\text { completion risk }\end{array}$ & $\begin{array}{l}\text { Design defects risks, risks of project examination and approval } \\
\text { delay, cost overruns risks, risks of the funding gap, delay completion } \\
\text { risk }\end{array}$ \\
\hline $\begin{array}{l}\text { Project } \\
\text { management risk }\end{array}$ & $\begin{array}{l}\text { Risk management cost overruns, temporary privatization project } \\
\text { risk, cause the risk of major accidents }\end{array}$ \\
\hline Market risk & $\begin{array}{l}\text { Major tourist products expected income risk, risk, income } \\
\text { insufficient risk insufficient market demand }\end{array}$ \\
\hline Credit risk & $\begin{array}{l}\text { Risk misallocation, franchise alteration of risk, the risk of unequal } \\
\text { income distribution }\end{array}$ \\
\hline Economic risk & Exchange rate risk, interest rate risk, inflation risk \\
\hline $\begin{array}{l}\text { Imperial kiln site } \\
\text { damage risk }\end{array}$ & $\begin{array}{c}\text { Force majeure risks, risks of geological conditions, land } \\
\text { demolition and compensation risk }\end{array}$ \\
\hline Political risk & Policy change risk, tax risk adjustment \\
\hline
\end{tabular}

Jingdezhen imperial kiln site to protect the PPP financing model application strategy Suggestions

\subsection{Jingdezhen government support, improve the regulatory system}

Jingdezhen imperial kiln site protection projects for the PPP financing model, cannot leave the Jingdezhen government's strong support and supervision. Jingde town government in the role of the PPP financing model is for the majority of the people to provide quality public services, in any case, all we should protect the interests of the state, protect the Jingdezhen imperial kiln site full of culture, and national service for the society, to be responsible for the imperial kiln site to protect the overall project planning, project bidding work, straighten out the rights of the private sector, take part in the project, regulate the private sector, set up the system of supervision, to ensure no loss of state-owned assets, ensure the reasonable development and utilization of imperial kiln site, do a good job performance evaluation, reduce the overall project and the potential risk 。

\subsection{Improve the PPP financing model of laws and regulations}

Since 2014, the state issued the national development and reform commission on the guidance of the government and social capital cooperation, the ministry of finance on promoting use of government and social capital on the cooperation pattern of notice and a series of PPP financing model guidance document, for the PPP financing model implementation frameworks and guide, but these are the guidance document, lack of certain operational, for the PPP financing model applied in the field of a specific not made specific provision in detail. Jingdezhen imperial kiln site protection projects for the PPP financing model belongs to the new field, to its existing responsibility, obligation and risk to have specific provision, in order to protect the interests of both sides 。

\subsection{The PPP specialized agencies and personnel support}

Jingdezhen imperial kiln site protection project of the PPP financing mode of operation, should adopt the way of franchising, financing, it is knowledge of legal, financial and financial aspects put forward higher requirements, the specialized agencies and personnel need to be familiar with the PPP financing, to develop social capital participants more regulations and standards of the PPP financing program, to the Jingdezhen imperial kiln site conservation project PPP financing operations to provide professional technical support and the PPP specialized services 。

\subsection{Change the traditional concept of site protection}

Area of the Jingdezhen imperial kiln site itself scale, the value is bigger, the maintenance cost is higher, the national government authorities every year to spend a lot of money, manpower and material resources to support, to ensure the maintenance of imperial kiln site needs. But the traditional way of site protection, bureau only mud in the general sense of the visit, thanks in part to protect need may not be able to visit, so can't highlight the true value of imperial kiln site, difficult to achieve its social benefits. Therefore need to change the traditional concept of heritage, the real 
play to highlight the value of imperial kiln site, in the protection of great importance to the development of her at the same time, both the social benefit, and generate economic benefits, realize the imperial kiln site project of social public welfare, improve the surrounding environment at the same time, promote the overall value of startan and economic feedback to social benefits, reduce the pressure on government finances.

\section{Acknowledgments}

Fund Project: This article is the Jingdezhen City social science planning project " PPP model research on Jingdezhen Royal kiln site protection" (Project number: 753005-011), Jiangxi province social science planning project " Nanchang, Jingdezhen construction innovation city advance Poyang Lake ecological economy District construction of the path study (Project approval number: 10YJ24) and in 2015 the Jiangxi Province College of Humanities and social science research project "'" Internet + technology + culture "three wheel drive transformation and upgrading of China's ceramic industry" (Project approval number: JJ1537) phased research results.

\section{References}

[1] Liang Dongling. The PPP mode construction project hidden risk research [D]. Northeast forestry university. 2014.6

[2] in the early dawn, the PPP mode Angola agricultural investment project financial management research [D]. China university of geosciences. 2014.12

[3] xiu-hui li, shi-ying zhang. The PPP: a new type of project financing mode [J]. China soft science. 2002.2

[4] jian-kun zhang, Wang Xiaorong li-fang wu. "ants" affordable housing PPP pattern design [J]. Journal of southeast university (philosophy and social science edition). 2012.3 